\title{
A Design Model for Lifelong Learning Networks
}

Citation for published version (APA):

Koper, R., Giesbers, B., Van Rosmalen, P., Sloep, P., Van Bruggen, J., Tattersall, C., Vogten, H., \& Brouns, F. (2005). A Design Model for Lifelong Learning Networks. Interactive LearnIng Environments, 13(1-2), 71-92.

https://doi.org/10.1080/10494820500173656

\section{DOI:}

$10.1080 / 10494820500173656$

Document status and date:

Published: 01/01/2005

Document Version:

Early version, also known as pre-print

Please check the document version of this publication:

- A submitted manuscript is the version of the article upon submission and before peer-review. There can be important differences between the submitted version and the official published version of record. People interested in the research are advised to contact the author for the final version of the publication, or visit the DOI to the publisher's website.

- The final author version and the galley proof are versions of the publication after peer review.

- The final published version features the final layout of the paper including the volume, issue and page numbers.

Link to publication

\section{General rights}

Copyright and moral rights for the publications made accessible in the public portal are retained by the authors and/or other copyright owners and it is a condition of accessing publications that users recognise and abide by the legal requirements associated with these rights.

- Users may download and print one copy of any publication from the public portal for the purpose of private study or research.

- You may not further distribute the material or use it for any profit-making activity or commercial gain

- You may freely distribute the URL identifying the publication in the public portal.

If the publication is distributed under the terms of Article 25fa of the Dutch Copyright Act, indicated by the "Taverne" license above, please follow below link for the End User Agreement:

https://www.ou.nl/taverne-agreement

Take down policy

If you believe that this document breaches copyright please contact us at:

pure-support@ou.nl

providing details and we will investigate your claim.

Downloaded from https://research.ou.nl/ on date: 26 Apr. 2023 


\title{
A Design Model for Lifelong Learning Networks
}

\author{
Rob Koper, Bas Giesbers, \\ Peter van Rosmalen, Peter Sloep, Jan van Bruggen, \\ Colin Tattersall, Hubert Vogten, Francis Brouns
}

Educational Technology Expertise Centre

Open University of the Netherlands

PREPRINT

\begin{abstract}
The provision of lifelong learning facilities is considered to be a major new direction for higher and distance teaching educational institutes catering for the demands of industry and society. ICT networks will in future support seamless, ubiquitous access to lifelong learning facilities at home, at work, in schools and universities. This implies the development of new ways of organizing learning delivery that that goes beyond course and programmecentric models. It envisions a learner-centred, learner-controlled model of distributed lifelong learning. We present a conceptual model for the support of lifelong learning which is based on notions from self-organization theory, learning communities, agent technologies and learning technology specifications such as IMS Learning Design. An exploratory implementation has been developed and used in practice. We reflect on the findings and future directions.
\end{abstract}




\section{Lifelong Learning Networks}

Both higher and distance education are currently exploring the new possibilities offered by eLearning. Today we find new, collaborative initiatives such as virtual universities, consortia and digital universities, which aspire to share learning resources, increase the quantity and quality of educational services, and explore new markets, particularly in the field of lifelong learning (Brookfield, 1987; Cross-Durrant, 1987; Jarvis, 1987; Smith, 1996, 2001). The underlying idea is that 'lifelong learning' will ultimately provide a major service catering for the needs and demands of industry and society as a whole (Tuijnman, 1992; Ragget, 1996; Schuetze, 2000). Lifelong learning is the concept that refers to the activities a person performs throughout their life to improve their knowledge, skills and competence in a particular field, given some personal, societal or employment related motives (Aspin \& Chapman, 2000; Field, 2001; Griffin, 1999).

To achieve these aims, educational institutions must offer facilities that meet the needs of learners at various levels of competence throughout their lives. People must be able to use lifelong learning facilities to upgrade their knowledge, skills and competence in a discipline as required. They can also contribute to the facilities by sharing knowledge and supporting other learners. Lifelong learners are not merely consumers of learning facilities, but can be asked to actively contribute to the facilities themselves (Fischer \& Ostwald, 2002).

A promising approach to lifelong learning is to use ICT networks to connect distributed learners and providers in a discipline to establish Learning Networks (LNs). ICT networks can support seamless, ubiquitous access to learning facilities at work, at home and in schools and universities. Learning resources from providers such as schools, companies, libraries and the learners themselves can be made available from a single point of access and learners can be helped to perform certain tasks more efficiently by including software support. The use of ICT networks implies the development of new ways of organizing learning facilities that goes beyond course and programme-centric models and envisions a learnercentred, learner-controlled model of distributed lifelong learning.

In this article we present a new design model for the organization of lifelong learning in ICT networks. The model is theory-based, and uses technologies such as software agents and open learning technology standards to establish an interoperable network of collaborating parties. First, we analyse the pedagogical, organizational and technical aspects of LNs. We 
then present an initial model for LNs that specifies the analysis in terms of requirements and formalizes the representation of an LN. Finally, we present our first attempt at implementing this model in a peer-to-peer network and discuss our findings as to whether the implementation fulfils the stipulated requirements.

\section{Analysis}

LNs can be studied from at least three perspectives: pedagogical, organizational and technical (Koper, 2004).

\section{Pedagogical Aspects}

An LN is a distributed set of people who interact to create and share units of learning in developing their competence in a particular discipline. It is a 'two-mode network' with two types of nodes: the members of the LN and the units of learning in the LN (Wasserman \& Faust, 1994; Degenne \& Forsé, 1999). The members define the learning community (LC) within the LN. The units of learning (UOLs) define the set of learning activities offered in the LN, for example courses, assessments, workshops or seminars. The core questions in this section are: How can effective LCs be developed? And how can effective UOLs be developed and used in LNs?

\section{Learning Communities}

Shaffer and Anundsen (1993) define 'community' as a dynamic whole that emerges when a group of people share common practice; are interdependent; make decisions jointly; identify with something larger than the sum of their individual relationships; and make longterm commitments to well-being (their own, one another's and the group's). Communities tend to be self-governed, self-organized and decentralized. Common goals and values and communal relationships are important moderators in forming communities. Communities have their own identity, which can change and evolve.

Wilson and Ryder (1998) characterize 'learning communities' (LCs) as follows: they have distributed control; there is commitment to the generation and sharing of new knowledge; learning activities are flexible and negotiated; community members are autonomous; there is a high level of dialogue, interaction and collaboration; and there is a shared goal, problem or project creating a common focus and incentives to work together.

Within the context of lifelong learning it is necessary to have an enduring membership of the community. Competence in a field evolves over a lifetime. An important requirement 
for lifelong learning is that the learning results are stored in a portable, standard way, for example in a portfolio. These learning results can be used to identify the LNs; position the person in the network; and provide a classification of the expertise of the person in the field. As seen from a lifelong learning perspective, a teacher is not a separate entity, but is a role that any lifelong learner can take, depending on their expertise, and relative to the expertise of whoever requires support. Anyone can start in a community as a novice and evolve into an expert. During his/her lifetime the person stays a member and is responsible for sharing knowledge and experience as required. The knowledge and support services in the community and the members' knowledge also evolve. In a permanent community, the community itself gets a structure and culture independent of the participants. We adopted this idea of lasting, evolving learning communities as a key principle for the design of LNs.

Lifelong learners must have easy, ubiquitous access to an LN, which should not be location or technology dependent. It should be accessible from anywhere by standard means of communication. In order to sustain it, it must support, among other things, interoperability standards that have been adopted, defined and agreed upon within the community.

\section{Units of Learning}

UOLs are developed and used in LNs and can serve various functions in them depending on the design, for example the introduction to a knowledge domain; acquisition of a skill; or assessment of acquired knowledge.

Members of an LN should be able to select the UOLs they need in order to attain certain expertise or competencies, given their pre-knowledge. When a UOL is selected, the person must be able to study it and provide feedback about it. When the UOL is used in practice, additional run time data can be added to the design, for example user and usage information, mail messages and forum contributions.

A UOL typically contains a learning design and learning resources. The learning design specifies the workflow in the teaching-learning process (Koper, 2001; Koper \& Manderveld, in press; Koper \& Van Es, 2004). At the abstract level, the learning design describes the following process: A person gets a role (e.g. lifelong learner) in a learning context. This role entails a set of learning activities for attaining some specified learning objectives. A learning design method, based on a pedagogical approach, determines which roles get which type of activity at a given time. The learning activities are performed in a learning environment provided with resources and communication facilities. The outcomes of the learning activities are also resources that are added to this environment. Properties are 
defined to keep track of learners' progress. In addition to learning activities, a person can also get a role to perform support activities to help others learn. This abstract learning design model is implemented in the IMS Learning Design specification (LD, 2003) to create interoperable learning designs.

The same learning design can be used with different resources and vice versa. The process of building UOLs from learning designs and resources is called 'aggregation'. Conversely, the process of breaking down the structure of a UOL into learning design and resources is called 'disaggregation'. These processes support the reuse of learning designs and underlying learning resources.

In order to develop effective UOLs, the learning design of the UOL should be based on an appropriate 'pedagogical model'. A pedagogical model prescribes an effective teachinglearning process for a class of learners to achieve a class of learning objectives in a class of situations. A learning design is an instance of a pedagogical model. It is a concrete application of a pedagogical model for a specific learning objective, a target group and a specific situation. Examples of pedagogical models are mastery learning, problem-based learning, active learning, or any teacher's notion about good teaching and learning practice. There is a wide range of pedagogical models. Some are better suited to specific disciplines, target groups, settings or learning objectives. However, there are no fixed rules for deciding which model is best in which situation (Reigeluth, 1999). At a high level of analysis, Merrill (2003) summarizes current pedagogical models as follows: ' $\ldots$ the most effective learning products or environments are those that are problem-centred and involve the student in four distinct phases of learning: (1) activation of prior experience, (2) demonstration of skill, (3) application of skill and (4) integration of these skills into real-world activities'. He further summarizes the underlying 'first principles of instruction' by stating that learning is promoted when: learners are engaged in solving real world problems; existing knowledge is activated as the foundation for new knowledge; new knowledge is demonstrated to the learner; new knowledge is applied by the learner; and new knowledge is integrated into the learner's world.

Merrill's analysis and the instructional design approaches he studied focus on a single learner in a problem situation. In LNs this has to be extended using the notions of learning communities, or more general, social-constructivist notions (Duffy \& Cunningham, 1996; Retallick, Cocklin \& Coombe, 1999; Hooff, Elving, Meeuwsen \& Dumoulin, 2003). One of the notions in social-constructivism is that knowledge is not absolute, but is relative to the interpretation and beliefs within communities of practice. This social notion of knowledge implies that facts, events, data and information can only be interpreted and acted upon when 
the social context is represented in the learning situation (Lave \& Wenger, 1991).

Bransford, Brown and Cocking (2000) summarize this broader perspective on teaching and learning, stating that effective education should be: learner-centred, taking the preconceptions of learners into account; knowledge-centred, paying attention to the subject matter and what competence or mastery appear to be; (formative) assessment-centred, providing feedback; and community-centred, taking care of the application context in the real world, sharing knowledge and developing values.

\section{Organizational Aspects}

The core question to be answered in this section is which principles we should apply in organizing an LN. As we have said, LCs tend to be self-organized. One reason is that the management of a large distributed network can be very complex. Different perspectives and powers have to be balanced carefully. A decentralized management approach such as selforganization is desirable. Another reason for introducing self-organization in LNs is to increase the efficiency of the learning support structure in LNs. Active learners in an LN produce work such as written contributions to discussions and research reports. These have to be read, reacted to or reviewed. In a traditional setting, there is a danger that these tasks will be assigned solely to the teacher, whose workload will then increase considerably. Our assumption is that the application of self-organization theory can be a foundation for the establishment of efficient systems with a minimum of planning and control, while maintaining maximum flexibility to adapt to learners' needs. This will reduce overhead costs for maintenance, planning, control and quality. This assumption is based on research into selforganization theory (Varela, Thompson \& Rosch, 1991; Maturana \& Varela, 1992), which is grounded in complexity theory (Waldrop, 1992; Kauffman, 1995) and studies the characteristics of the social organization of communities that 'emerge' from the interactions of lower level actors. It deals with the way macro-phenomena occur as emergent behaviours from the activities of the subsystems at the micro-level (Prietula, Carley, \& Gasser, 1998, p.14). The social organization that emerges (e.g. trust, grouping, role specialization, action coordination, distribution of tasks and resources, conflict resolution, quality norms and interaction standards) in its turn imposes behavioural constraints on the actors and provides for social objectives (Ferber, 1999; see Figure 1). 


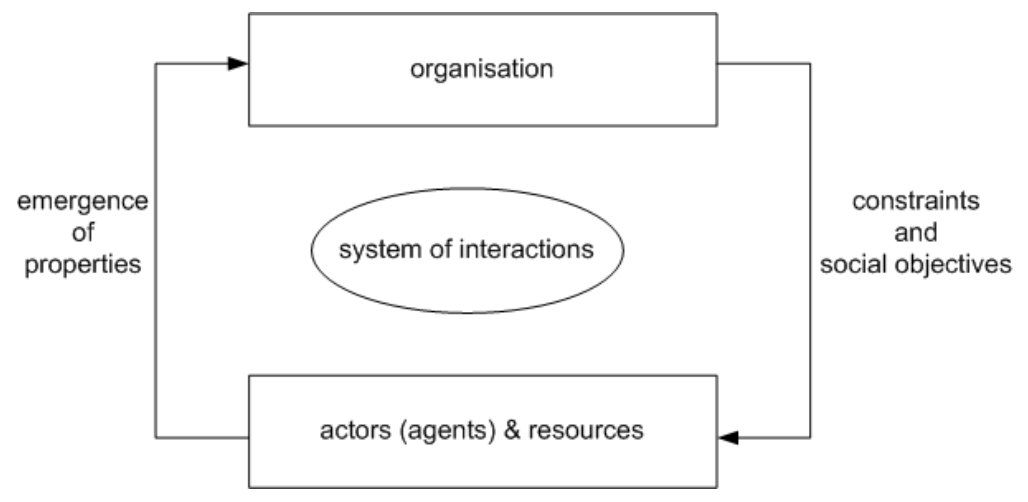

Using this perspective, the organization of lifelong learning can be realized by installing technical facilities that enable distributed interactions among participants directed at a common purpose (e.g. competence development in a disciplinary field), governed by policies that stimulate participants to learn, share knowledge and support each other. The management and application of policies in an LN is termed 'sociability' (Preece 2000, p. 26-17). Sociability governs social interaction in a community. It cannot be controlled directly, but can be supported by carefully communicating the purpose and policies of the community. Preece (p. 95-96) identifies several policies in a community: joining or leaving requirements; by-laws; codes of practice for communication; rules for moderation; issues of privacy and trust; practices for distinguishing professionally contributed information; rules for copyright; and democracy and free speech in the community. We identify the policies in LN in terms of: objectives and values; terms of use; membership/role policies; standards and quality policies; and reward policies.

An important factor in establishing self-organization is the creation of first-order and second-order feedback mechanisms. First-order means that people in the community know what their counterparts are doing or have done regarding the UOLs in the network. This provides information for navigation and behavioural models within the community. Secondorder refers to feedback about the emergent properties in the system: what is the performance of the community and how is it organized (Gilbert, 1995)? For instance, there is no centralized quality control in the LN. It is expected that the network will uphold a range of quality levels, but that the feedback mechanisms (e.g. reviews and ratings) will ensure that on average satisfactory quality is maintained. Thus, factors such as development costs, frequency of use, incentives, price and satisfaction may be dynamically balanced.

Most effective self-organization systems in nature (e.g. ant colonies) depend on some 
specialization of roles that perform tasks simultaneously. However, this role-specialization is functional. Individuals can change roles when the demand for a certain activity increases (Bonabeau, Dorigo \& Theraulaz, 1999).

The activities of persons in an LN are influenced by the reward system established in it (e.g. personal need, reputation, money). A theory about reward is elaborated in social exchange theory (Thibaut \& Kelly, 1959; Constant et al., 1994). The reward system is typically implemented in the policies of an LN.

We want to stress that self-organization implies organization. It is not a synonym for chaos, anarchy or disorganization. The structures that result from self-organization can, in principle, be the same as those proposed by central agencies, except that democratic principles determine the hierarchy and organization.

\section{Technical Aspects}

The core questions to be answered in this section are: How can we establish an interoperable network with distributed lifelong learners, distributed support organizations and a variety of different units of learning? And how can we support the actors in the network to perform their tasks as efficiently as possible? The first is related to interoperability specifications and standards; the second to usability and software agents.

\section{$\underline{\text { Interoperability specifications }}$}

In order to establish a network of interacting entities in a technical sense, it is necessary for the entities to use the same underlying standards to support connectivity and exchange. For example, Internet protocols enable the connectivity of millions of computers around the world to establish a network. The entities in an LN also need to be standardized, at least within the community, if they are to connect. A learning resource created in location $\mathrm{Y}$, using infrastructure X, should be usable in location Z, using infrastructure W. Standards can be defined solely within a community or LN. However, it is good practice to use existing open standards and specifications wherever possible. Several open interoperability specifications have been developed, most of them by IMS (imsglobal.org), IEEE (ltsc.ieee.org) and AICC (aicc.org).

Various standards have to be set to establish LNs. The portable coding of the learning resources or knowledge must be specified (e.g. XHTML for non-binary resources). Metadata standards such as LOM (2003), Dublin Core (2003) or RDF (2003) can be used to describe the learning resources. The IMS Question and Test Interoperability Specification (QTI, 2003) 
can be used for testing. However, after agreement on the set of general standards available for an LN has been reached, discussions have to continue about the customization of standards and the development of additional specifications.

A critical specification for LNs is IMS Learning Design (LD, 2003). LD implements the abstract learning design model discussed above. It enables the representation of the learning and teaching processes in a UOL to be interoperable and machine interpretable. It provides a framework for including learning activities, support activities, assessment and learning or knowledge resources. LD can express the pedagogical approach taken in the UOL, and supports personalization of learning routes and reusability (Koper \& Van Es, 2004).

\section{Usability and Software Agents}

An LN's usage may be hindered if it is too complex, is unpredictable or contains errors. These factors are addressed in 'usability'. An LN is usable when it supports rapid learning, high skill retention, low error rates and high productivity. It is consistent, controllable and predictable, making it pleasant and effective to use (Preece 2000, p. 26-27). The problem with usability is that it competes with the flexibility and complexity of a system. More flexible systems have more options that tend to overload the cognitive system when not properly designed (Paas \& Firrsova, 2004). Measures such as adaptable interfaces, help systems and training facilities can be used to increase the usability of the LN, but so can software agents help users perform their tasks more easily and efficiently. Software agents can be used to automate tasks normally performed by people, or support people in doing certain tasks more effectively or efficiently. Software agents are computational systems that inhabit a complex, dynamic environment, can sense and act autonomously in this environment, and in doing so achieve a set of goals or tasks they are designed for (Jennings, 1998). There are two approaches to implementing software agents: the single (complex, intelligent) approach; and the multi-agent approach (multiple agents, low intelligence, simple). These can be considered as two different paradigms. Multi-agent systems are loosely coupled networks of entities that have the following characteristics: each agent has incomplete capabilities to solve a problem alone; there is no global system control; data is decentralized; and computation is asynchronous. According to Ferber (1999), these systems have skills in social organization, cooperation, coordination, negotiation and communication. The principles of self-organization are applied in software in these multi-agent systems.

The quality of the tasks performed by software agents is dependent on the technical advancement of these agents and the state-of-the-art in the field. Some possibilities are: agents 
help users search for information using semantic web principles (Berners-Lee, Hendler, \& Lassila, 2001); agents help answer e-mails with certain common characteristics; or agents help organize and plan the activities in an LN.

\section{Design of a Learning Network}

Based on the principles of units of learning, learning communities, self-organization, interoperability specifications and software agents, we developed a design framework for LNs. We will present this design by summarizing the requirements model and outlining a formal representation of an LN. First, we need to introduce the concept of an 'Activity Node' to formalize the design. Like any network, an LN can be represented as a graph with nodes. However, an LN is a two-mode network, with the nodes being LN members and UOLs. In the following sections we will aggregate the two modes into a single node, called an Activity Node (AN). An AN contains all the runs of all the versions of a UOL, including information about the members who are (or have been) active in it and the information the members have produced about it (e.g. feedback, completion data). Moreover, it contains a set of rules that govern its lifetime, specifically its 'fading out' and 'staying alive' behaviour. There are subtle differences between a UOL, a UOL run, and an AN. A UOL is the learning facility that is abstractly defined for any set of learners at any time. A UOL run is its instantiation for a specific set of learners in a certain time frame (e.g. a class, the actual run of a workshop). An $\mathrm{AN}$ is the set of all possible runs for different versions of the UOL.

\section{Requirements}

In the analysis section, several statements about LNs were formulated that can be translated into general requirements for LNs (see Table 1). 
Table 1 (General Requirements for LNs)

\begin{tabular}{|c|c|}
\hline No. & General Requirement \\
\hline R1 & $\begin{array}{l}\text { The objective of any LN is to offer long lasting, evolving facilities for the members to improve } \\
\text { and share their expertise and build the competencies needed in a disciplinary field. }\end{array}$ \\
\hline R2 & $\begin{array}{l}\text { The LN should offer facilities for members to create, search, get/access and study LNs, ANs, } \\
\text { UOLs and learning resources as a means of building expertise and competence. }\end{array}$ \\
\hline R3 & $\begin{array}{l}\text { The LN should be governed by community policies that reflect the common goals and values of } \\
\text { the membership. Instruments must be available to manage, change and apply the different policies } \\
\text { (LN objectives and values, terms of use, standards and quality, reward system, membership } \\
\text { policies). }\end{array}$ \\
\hline R4 & $\begin{array}{l}\text { The LN should have facilities to assign its members to specialized roles according to certain role } \\
\text { policies. Roles are not fixed. Role change policies must be available. }\end{array}$ \\
\hline R5 & $\begin{array}{l}\text { The LN should offer facilities to search for ANs and UOLs that match the members needs and } \\
L N s \text {, and should support flexible learning routes (positioning, logging of tracks of others and } \\
\text { usage patterns). }\end{array}$ \\
\hline R6 & $\begin{array}{l}\text { The LN should contain ANs and UOLs for different levels of expertise to serve a heterogeneous } \\
\text { membership. }\end{array}$ \\
\hline R7 & $\begin{array}{l}\text { The LN should offer ANs and UOLs in which learning designs are based on pedagogical models } \\
\text { that are selected as suitable for the discipline, the membership and the learning objectives (e.g. } \\
\text { problem-based and learner-centred, formative assessment, knowledge and community-centred). }\end{array}$ \\
\hline R8 & $\begin{array}{l}\text { The LN should facilitate a high level of dialogue, interaction and collaboration within the LN and } \\
\text { within ANs. }\end{array}$ \\
\hline R9 & The LN should support guidance/scaffolding, or more generally: support activities. \\
\hline R10 & $\begin{array}{l}\text { The LN should support distributed control. The LN managers are LN members with specific } \\
\text { assigned management tasks (according to the change policies). }\end{array}$ \\
\hline R11 & $\begin{array}{l}\text { The LN shoud provide first order and second order feedback to all members to support the } \\
\text { optimization of organization and quality according to self-organization principles. }\end{array}$ \\
\hline R12 & $\begin{array}{l}\text { An explicit exchange reward system which is consistent with self-organization principles should } \\
\text { be available in the LN. }\end{array}$ \\
\hline R13 & The LN should have distributed, ubiquitous access. \\
\hline R14 & $\begin{array}{l}\text { The LN should have facilities to provide automated support (software agents) for some members' } \\
\text { tasks to make performance more efficient. }\end{array}$ \\
\hline R15 & $\begin{array}{l}\text { The LN should use community standards for interoperability (e.g. units of learning, learner } \\
\text { dossiers, learning/knowledge services and resources) and provides facilities to discuss and change } \\
\text { these. }\end{array}$ \\
\hline R16 & $\begin{array}{l}\text { The LN should find the right balance between usability for the participants and } \\
\text { flexibility/complexity (information/training facilities, adaptable user-interfaces, error free } \\
\text { technology). }\end{array}$ \\
\hline
\end{tabular}


These requirements can be elaborated in a 'use case model'. Use cases are abstractions of scenarios in which the concrete behaviour of persons within a system, or using a system, is described (Fowler, 2000; Cockburn, 2001). A use case model contains, among other things, use cases, actors and relationships (Armour \& Miller, 2001) . 'Use cases' (the ellipses in the diagrams in Figure 2) are sequences of actions required of the LN to function properly. The 'actors' (the stick figures) are the persons or software agents that initiate the use cases, perform them or benefit from them. 'Relationships' (the lines in the diagrams) link two elements to show the interaction. The diagram in Figure 2 is drawn according to the UML specifications (OMG; Booch, Jacobson \& Rumbaugh, 1999).

Figure 2 Use Case Model for Learning Networks

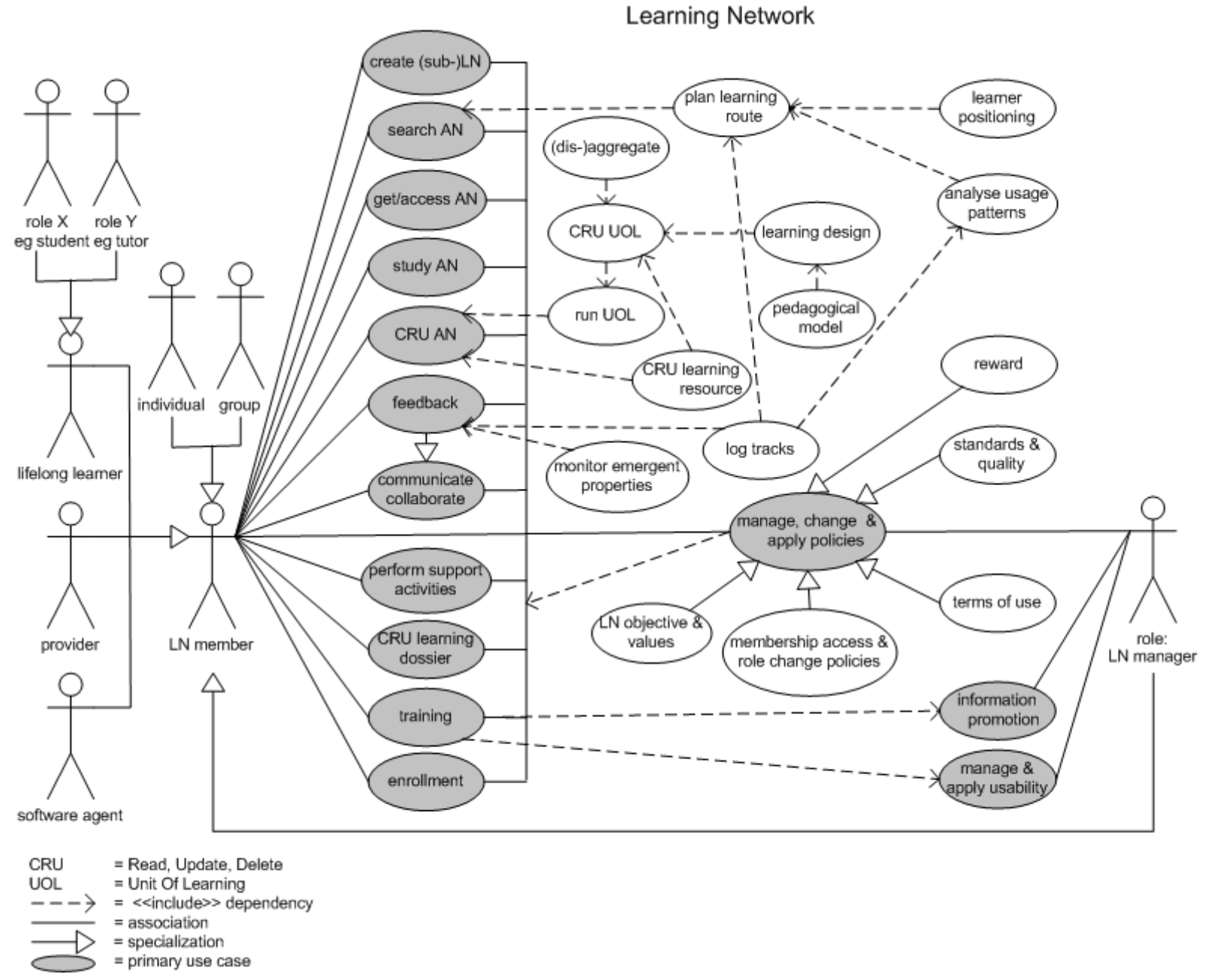

There is only one actor in an LN, the LN member. There are three types of LN members: lifelong learners (primary actors), providers and software agents, each of which can 
play roles in the management of the LN. Members can act individually or in groups. Groups can be formal (e.g. company employees) or informal. Software agents can, in principle, perform the same use cases as any of the human actors, but in most situations they will support a human member in performing a specific use case. Lifelong learners have specific expertise and competence in the discipline and these must be registered and updated in a learning dossier. The competence and expertise levels stored in the dossier must be standardized to be able to position a learner in an LN. A key notion in LNs is that lifelong learners can perform all the use cases, including those that are traditionally the responsibility of teachers. Control is expected to be distributed democratically using a set of agreed policies. Providers can be educational institutions, companies and libraries that provide lifelong learners (e.g. employees), the learning services (e.g. tutoring services) or the learning resources (e.g. books, CDs).

LN members can perform a variety of primary use cases, for example search an AN to plan a suitable learning route; get or access an AN; study an AN; or provide feedback about an AN. Figure 2 shows the primary use cases as grey ellipses. The other use cases are specializations of a primary use case or are included in them.

\section{Formal Representation of a Learning Network}

Using the AN concept, we can represent the formal structure of an LN as a graph in disciplinary domain $D$, with ANs as its nodes $\{\mathrm{a} 1, \ldots, \mathrm{ai}\}$. 
Figure 3 (a) A track of completed activity nodes for a single learner; (b) a pre-planned route a learner can follow

(a) Track

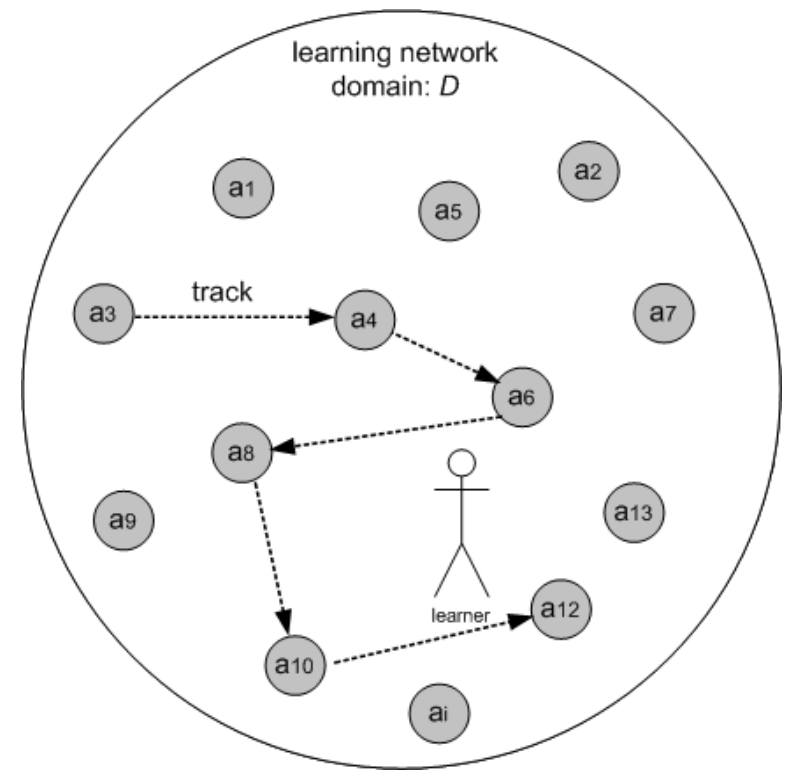

(b) Route

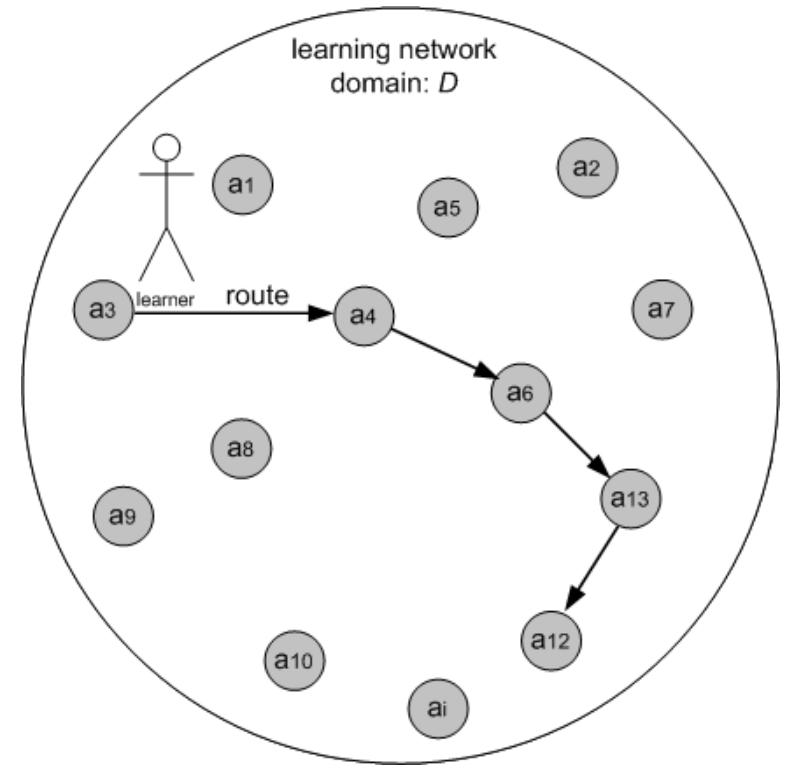

Actors travel in an LN from AN to AN, leaving their tracks in each. The sequence of ANs completed by learners is a 'learning track' (see Figure 3a). The information in any two ANs must be designed so that it can be analysed. (How many learners travelled from the first to the second AN or vice versa? What are the usage profiles of the learners and the perceived quality of the path?)

Learning 'routes' are paths that are planned (Figure 3b). In traditional educational settings, teachers or instructional designers are responsible for this. A different approach to creating routes is to share learning tracks and experience of them between participants in an LN. This can be a single track or an analysis of the aggregated, collective tracks from a set of participants to determine the most successful routes. This data is expected to help actors navigate in the LN, specifically when additional maps and facilities are created, for example the possibility of matching a user's current usage profile with the average profiles of users who followed a particular track. In this approach, routes are based on real practice rather than theoretical instructional design principles. It opens the possibility of adding this inductive route design to the current theoretical, deductive design approaches (Koper \& Sloep, 2003).

Another important concept is the learner's 'position' in the LN (Figure 4, the set $\{\mathrm{a} 4$, a8, a 10$\}$ ). This is defined as the set of ANs completed in the LN. An AN is completed when the user completes any of the runs of the UOL that are contained in the AN. We identify the notion of a 'target' in an LN. A target is any set of ANs connected to a particular level of 
competence or expertise in the domain (Figure 4 the set $\{a 1, \ldots, a 8\}$ ). A target can have one or more formal assessments (a specific kind of $\mathrm{AN}$, or integrated into one or more ANs) included to certify a competency. The difference between the set of target nodes and the set of position nodes defines the set of ANs that a learner must perform to reach the target. Figure 4 shows a 'to-do list', the set $\{a 1, a 2, a 3, a 5, a 6, a 7\}$. Given this list, a learning route can be established, by deciding on the order in which the ANs are taken (e.g. first a1 and a2, then a5 and so on.). This decision can be based on the tracks of successful, comparable others in the LN. A learner can also follow a more exploratory route or can change routes on demand. Ultimately this will also create a track that can be shared.

Figure 4 Illustration of the Concepts Position and Target

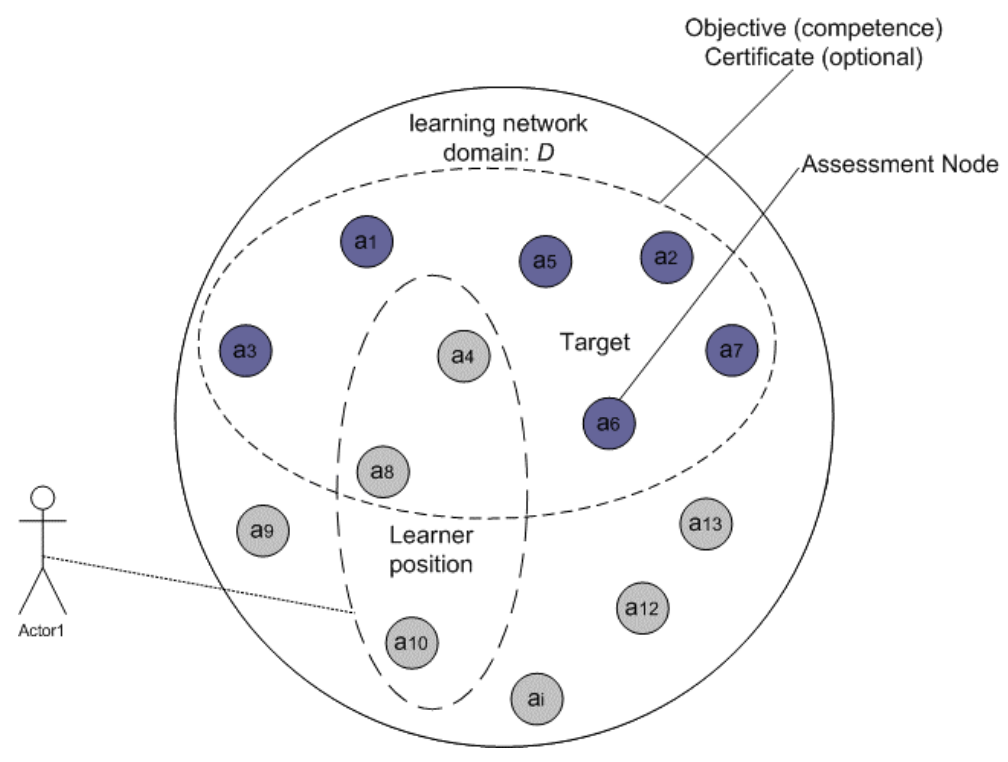

\section{Implementation}

We created a prototype based on the principles discussed above. In order to save costly programming time, we selected a platform we could customize to fulfil the requirements as far possible. We selected the Groove (Groove.net), a fairly easy to customize, peer-to-peer collaborative environment. The Groove uses a concept of shared workspaces. A workspace can be created by any user (manager), who may then invite others to join the workspace in the role of manager, participant or guest (with different rights attached to each role). Users with the appropriate rights can add tools to the workspace from a predefined tool-set, such as discussion forums, shared files, collaborative writing, shared web navigation tools and shared 
calendars. Users may use the tools according to their roles. An important feature is that all users share the same tool-set. No user is privileged to access any special tools. This satisfies one of our major criteria for self-organized LNs. Policies can be communicated and implemented by setting user-rights.

The above-mentioned design has been implemented as follows:

1. An LN is a workspace with a name that starts with 'LN:'.

2. An AN is a workspace with a name that starts with 'AN:'

3. Learning and support activities are modelled as records in a database with forms (using the Groove Form tool).

4. Activity structures (sequences and selections) are created by organizing the sequence of the activities in a list and by providing extra textual information about the sequencing (see Figure $5)$.

5. Learning objects and services are links within the activity record with specific tools and resources in the environment (see Figure 6).

6. An environment is modelled as a labelled group of tools and services in the Groove.

7. The learning objects are contained in a files tool within the environment.

8. Services, specifically discussion forums, sketchpads and outliners are included in the environment as separate tools.

9. Tracking and monitoring is implemented by asking learners to provide the necessary information in a form.

10. Membership of the LNs and ANs is made visible by the Groove (including on-line/off-line status and published profiles).

11. Navigation is supported in two ways: First, the Groove provides a list of ANs to select from; second, we provide a sequenced list of ANs. The preferred route is modelled by listing each $\mathrm{AN}$ as a message in a discussion tool. The access files that the Groove needs to access the ANs are attached to the messages. They are updated for every new AN that is developed. 12. Communications and collaborations that are not related to specific LNs or ANs are supported by the standard communication facilities of the Groove (e.g. chatting and setting-up workspaces for sub-groups). 
Figure 5 Implementation of Activities (names of persons have been changed)

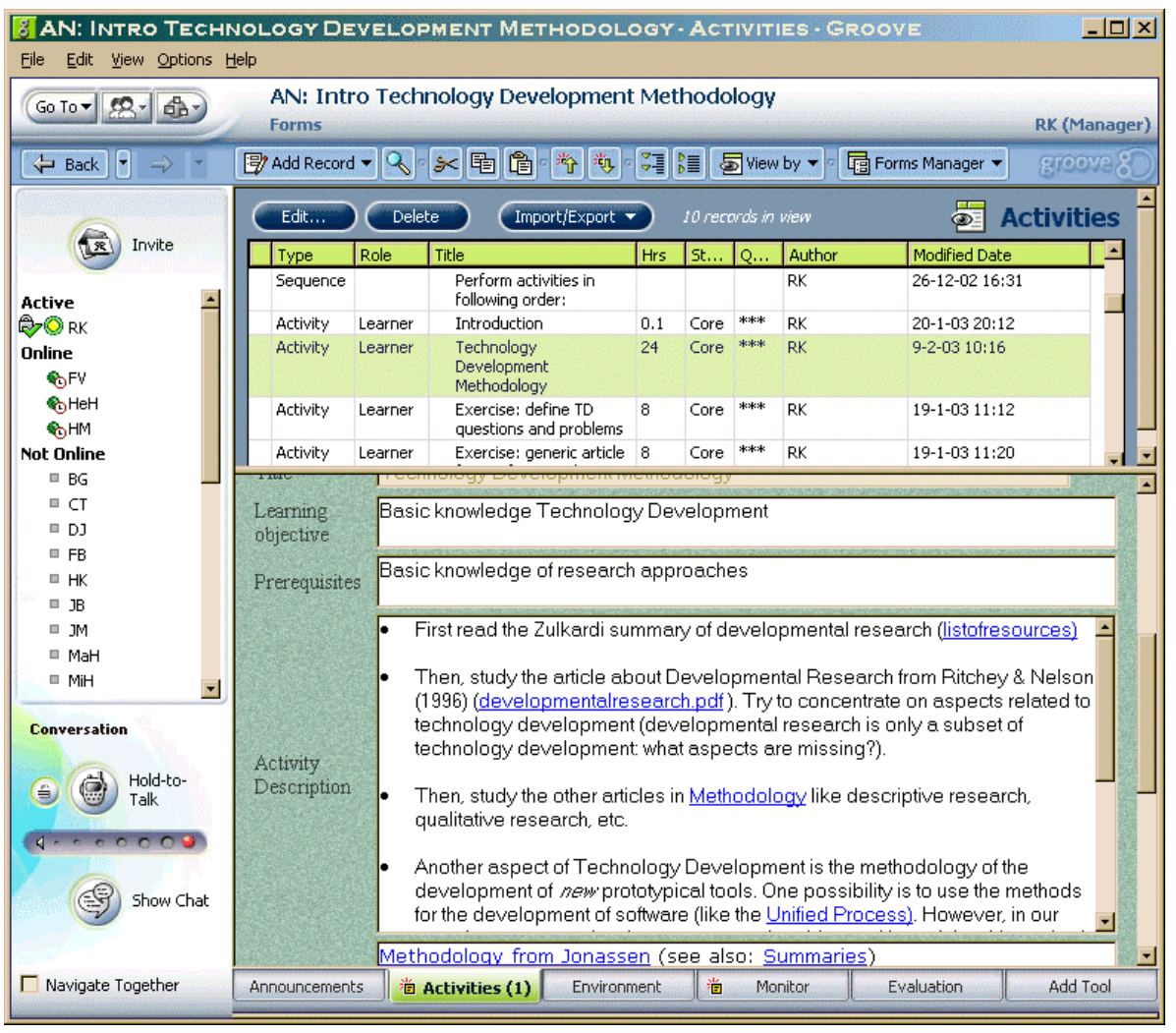

Figure 6 Implementation of Environment

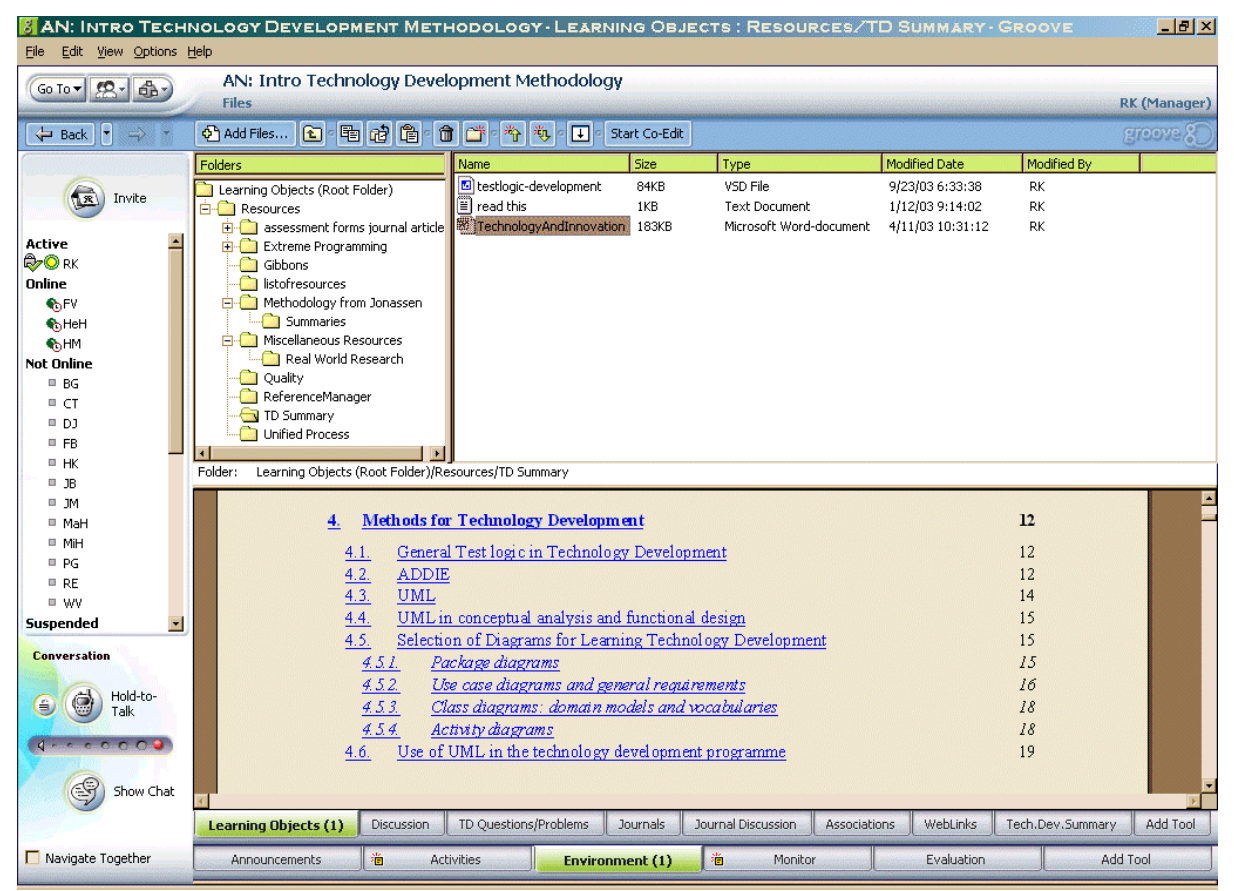




\section{Initial Experience}

This article focuses on the presentation of the LN framework. However, some preliminary work has been done by applying the Groove implementation of the LN framework in our own institution. The data obtained is mainly qualitative and is used to address the question whether (and how) the design requirements as specified in Table 1 can be implemented in an ICT environment.

In our study there were 25 participants ( 7 women; 18 men; mean age $39 ; S D=7.27$ ) in the LN in the domain 'Research and Technology Development in eLearning'. They needed to know more about various topics to perform better at work. The learners could be classified as learners with 'work-related motivation for professional training'. Two participants were junior, five senior. Everyone made two days a week available for this activity for six months. There were weekly plenary sessions (six hours) and distributed work (at home or at work). Participants sometimes worked in the whole group and sometimes in sub-groups.

A pre-knowledge self-assessment was administered. Participants rated their perceived knowledge and skills using 37 questions in 10 categories. There were four open questions and 33 items to be rated on a five point scale, ranging from 1 (no experience/knowledge/skill) to 5 (expert experience/knowledge/skill).

The LN implementation in the Groove was used during the face-to-face settings (participants had their lap-tops set up) and during individual work at home or at work. Only one LN was needed for this pilot. The route described was simple: start with two introductory ANs and then study the other available ANs in any order, taking the planning of plenary sessions around various ANs into account. All the members were involved in the creation and support of one or more ANs. In the first few weeks, an inventory was made of the desired ANs in the domain. Twenty-two ANs were identified, and the work in developing the ANs was divided among the participants. In each case at least one of the participants had experience of the field. The ANs became available within two months and could be categorized into the following groups: ANs providing an introduction to a topic related to future work $(N=9)$; ANs that fill pre-knowledge gaps in specialized domains $(N=13)$; ANs that were easy to construct as material was available, although they were not really tuned to the needs expressed in the initial list of ANs. These were mainly created to gather experience in $\mathrm{AN}$ development $(N=2)$. Eight ANs had corresponding plenary sessions.

Every week, the participants were asked to provide general evaluative comments in the Groove. More specific comments could be provided in every AN. The evaluative comments 
were discussed during the plenary sessions. After four months, participants were asked evaluate the usability of the Groove by reacting to one proposition ('learning the Groove was easy for me') and answering two open questions.

Community policies were developed and discussed in the opening session. The text was available in the first AN. Three policies were defined: describe and share your personal learning activities with others; be aware of quality and try to help others improve; and contribute regularly. Further agreements were made alongside these policies, although they were not recorded in a single policy document. An example is the policy that the creators of a $\mathrm{AN}$ are also responsible for supporting learners in that $\mathrm{AN}$.

The results are presented and discussed below according to the requirements specified in Table 1. The R-numbers refer to the requirement numbers in the Table.

R1 ('building expertise in the eLearning field') was satisfied. This goal has a rather permanent character related to the professional tasks.

R2 (ANs as a means of constructing/sharing knowledge) was satisfied. All the participants were involved in creating new ANs and used the system to search, access and study ANs in the LN.

R3 (policies) was satisfied. Of the three policies that were discussed, the first was rather difficult to attain. At the beginning, we experimented by creating new or improved alternative learning activities that everyone could add to the activity list. However, the Groove did not keep track of the new versions of improved learning activities, resulting in some confusion. This was mentioned in several evaluations and discussed in one of the plenaries. We decided to discontinue the policy of participants improving on each other's learning activities. A more successful means of implementing this policy was to ask them to build new ANs. The second policy was quite well established in the community. Participants commented on each others' productions ('I think you made a mistake in learning activity X ...'; 'You can also refer to this journal article for an overview'; 'I find the design of this AN rather boring. Can you include some problems to work on?'). These comments were generally made in the discussion forums.

The last policy was not too difficult to establish because of the weekly plenary sessions. However, some people experienced technical problems that prevented them from contributing. In retrospect, we think that it is desirable to have a limited set of policies, such as the three pilot policies, but that the first should be amended as follows: 'Describe and share your experience with others (i.e. produce ANs; contribute to discussions; provide feedback; and offer support)'. 
R4 (specialized roles) was satisfied. Depending on their level of expertise, anyone could assume any role in principle: learner, discusser, teacher, content developer, and so on. The owner of an AN decided on the participants' roles, which could be changed at any time. R5 (flexible learning routes) was partly satisfied. In principle, participants were free to identify the topics that could be elaborated in the ANs; everyone was stimulated to create any additional ANs; and everyone was free to select ANs in any order. Learner positioning, tracking, calculation of learning routes and the analysis of usage patterns was implemented manually.

R6 (heterogeneous) was satisfied. The self-assessment score was $M=3.27, S D=1.09 ; N=$ 24; Minimum score $=1.75$, Maximum $=4.50$. Nine participants scored below the mean. Some scored high and others low on the pre-knowledge questions. This provided the basis for planning AN development.

R7 (pedagogical models) was partly satisfied. The implementation supported the exchange of knowledge and was community-centred, although there were restricted facilities for formative assessment. Some ANs were designed to be learner-centred, but most introduced background knowledge in a particular area (e.g. introduction into XML and learning technology standards), without taking learners' preconceptions into account.

R8 (interaction) was satisfied. Intensive discussions took place among participants about the variety of topics provided in the LN. Most discussions were in face-to-face settings, plenaries, or sub-groups. Discussion groups were not really needed because of the face-to-face possibilities.

R9 (support) was satisfied. The policy that 'creators are tutors' was responsible for the fulfilment of this requirement.

R10 (distributed control) was satisfied. Everyone could take the initiative to set-up a new AN, start a discussion, or plan a topic for the plenaries, and everyone had an equal opportunity to use the Groove implementation. However, participants sometimes misinterpreted the rights management system. The creator of an AN can decide which user rights he/she gives the participants. These can be the same as the creator's, or more restricted. Being in a AN which is created by someone else and results in restricted rights (e.g. in deleting files) can make people feel control is not distributed and is too restricted. This is true for that specific AN, but not for the LN as a whole, where different ANs are controlled by different participants. R11 (feedback) was partly satisfied. First-order feedback was provided by facilities in the Groove. People could see who was on-line, who had contributed messages, who was doing what, when. Second-order feedback was not available. This was unfortunate, because the 
success of collaboration could not be monitored accurately and triggers for change could not be derived.

R12 (reward system) was not satisfied. There was not an explicit reward system designed and installed for the LN but, of course, the regular employee reward system of the institute (salary etc) was present in the background.

R13 (ubiquitous access) was partly satisfied. People can work on-line and off-line, and even direct cable connections between computers (without a central server) were used in the plenary sessions. However, the types of platform to access the LN were not free and the Groove only supports MS Windows. Moreover, the LN was not accessible though browsers. R14 (software agents) was not satisfied. There were no agents or other automatic facilities to support users.

R15 (standards) was partly satisfied. Technically, the Groove implementation was the imposed standard and allowed for connectivity between the members. However, no mechanisms were installed to discuss and adapt the standards. Other standards, such as dossier and competence standards, were not discussed or defined. This was less necessary as the group did have an organizational structure of competence (junior to senior).

R16 (usability) was partly satisfied. ANs were constructed, and people communicated with each other in the Groove. This means that the implementation has at least a minimum level of usability. The reactions to 'learning the Groove was easy for me' were $M=3.18 ; S D=1.10$; $N=22$. The open questions provided detailed information about the pros and cons. However, the participants primarily indicated negative points they experienced in working with the Groove implementation. Six participants complained about the usability of the Groove (hard to learn and to navigate). There were also some technical complaints. Participants responded to the open questions as follows: no search facilities (8 participants); very slow, low performance (6); no version control: data can be overwritten without the possibility of tracing previous versions (3); difficult to move the Groove from c: to d: drive, which is necessary because of the partitioning of hard disks and the large amount of local data needed for the Groove (>1 GB for all the ANs) (3); computer crashes (2); synchronization problems (1). Positive remarks were that the platform offers vast possibilities (3); 'I am able to see what others do' (2); and 'I am able to communicate with others' (2).

Another aspect of usability is navigation and overview. When the larger number of ANs became available, people began to lose their overview. Navigation and selecting relevant activities and resources became a problem. This overload disturbed personal planning and motivation. 


\section{Discussion}

The findings showed that we were able to implement most requirements except for R12 (reward system). It was not necessary to implement such a function in a rather closed situation where it is a part of someone's job to participate in the LN. However, it seems to be a crucial function in more open, distributed, larger LNs. Issues such as internal/external motivation and financial versus other rewards (fulfilment of personal needs, reputation) have to be elaborated. Further, more generic economic principles such as the exchange mechanisms in LNs need further study, specifically how to reward active participation and contributions of particular qualities in the LN. An analysis of the implications of theories such as the social exchange theory (Thibaut \& Kelly, 1959; Constant et al., 1994) for LNs is required.

Several requirements were only partially implemented, namely: R5 (flexible learning routes), R7 (pedagogical models), R11 (feedback), R13 (ubiquitous access), R15 (standards) and R16 (usability). To create flexible learning routes one needs to develop: a framework for the assessment of the learner's position in the LN; a method to define targets in it; a method to calculate learning routes; and a method to analyse usage patterns. These topics will be further explored in our future work. To support the use of adequate pedagogical models (R7), better design tools should be developed or selected. With respect to R11, a future system should include enough tracking data to be able to provide second-order feedback. Ubiquitous access (R13) is another issue that should be elaborated. We envision that in a future LN, participants will be able to use whatever tools they want in any situation (at home, at work, or 'on the road'), given compliance with certain standards. They may prefer their own e-mail and chat systems to functions built into the LN application. The groove offers good facilities for offline work, but at the price of using a specific client instead of the more common Internet browser. With respect to standards (R15), we need to address the issue of competence more than we did in this implementation. We had rather few ideas about a learner's position in the $\mathrm{LN}$, and these ideas were not specific enough for us to measure progress. This should be improved. The last partially satisfied requirement was usability. We reported on learnability, technical problems and the lack of overview for navigation purposes. All these issues are related to the usability of the Groove. Not much can be done to improve usability within the current features of the application. For future implementations we will explore other technologies to implement an LN. More specifically, we are considering using an integrated 
set of open source tools to implement the different functions of an LN. The general idea is that to implement LNs, it is necessary to keep the following objective in mind: in facilitating distributed lifelong learning, technology should help establish the LN and not be a barrier.

\section{Conclusion}

We have presented a framework for the design of a distributed network to support future lifelong learning based on self-organization principles and technologies such as LD, agents and ICT networks. In order to explore how to implement the requirements, we created a prototype and applied it in practice. The study is still in its exploratory phase. A great deal of work remains to been done to refine the framework, improve the implementation and evaluate the effectiveness and usability of the facilities in practice. We have already discussed further work in feedback for navigation, learner positioning, calculation of learning routes based on positions and targets, suitable reward systems and the use of software agents. A key question which has not been answered in this study is the relative contribution of the different requirements for the establishment of effective, efficient, attractive, accessible lifelong learning. The possibility of measuring the effects and relating them to the requirements has yet to be dealt with.

We will reconsider the use of the Groove as a platform. Although the Groove provided us with the possibility of easily implementing some of the use cases from the LN framework, it was not without its disadvantages. In addition to the functional requirements, the main issues for selecting and developing tools for LNs are: technical stability; performance; sustainability; scalability; the use of open standards; and the use of commonly available tools such as e-mail and web-browsers.

Given the growing societal needs for good, persistent, distributed, interoperable facilities for lifelong learning, there is a great need for further exploration and development of LNs as we have discussed above.

\section{Acknowledgements}

The authors wish to thank the management and staff of the Schloss Dagstuhl International Conference and Research Center for Computer Science for providing a pleasant, stimulating and well-organized environment for the writing of this article. 


\section{References}

Armour, F., \& Miller, G. (2001). Advanced Use Case Modeling. Upper Saddle River, NJ: Addison-Wesley.

Aspin, D. N., \& Chapman, J. D. (2000). Lifelong learning: concepts and conceptions. International Journal of Lifelong Education, 19(1), 2-19.

Berners-Lee, T., Hendler, J., \& Lassila, O. (2001). The Semantic Web: A new form of Web content that is meaningful to computers will unleash a revolution of new possibilities. Scientific American(May 17).

Bonabeau, E., Dorigo, M., \& Theraulaz,G., (1999), Introduction, in Swarm Intelligence, Oxford University Press

Booch, G., Rumbaugh, J., \& Jacobson, I. (1999). The Unified Modeling Language User Guide. Reading: Addison-Wesley.

Bransford, J, Brown, A.L., \& Cocking, R.R. (Eds.) (2000), How People Learn: Brain, Mind, Experience, and School: expanded edition. Washington: National Academy Press

Brookfield, S. (1987). Eduard Lindeman. In P. Jarvis (Ed.). Twentieth century thinkers in adult education (pp. 327). New York: Croom Helm.

Cockburn, A. (2001). Writing effective use cases. Boston: Addison-Wesley.

Constant, D., Kiesler, S. \& Sproull, L. (1994) What is mine is ours, or is it? Information Systems Research, 5 (4), 400-422.

Cross-Durrant, A. (1987). Basil Yeaxlee and the origins of Lifelong education. In P. Jarvis (Ed.). Twentieth century thinkers in adult education (pp. 327). New York: Crook Helm.

Degenne, A., \& Forsé, M. (1999). Introducing social networks. London ; Thousand Oaks, Ca.: SAGE.

Dublin Core (2003). Dublin Core Metadata. Website. Retrieved October 3, 2003, from http://dublincore.org

Duffy, Th.M., \& Cunningham, D.J. (1996). Constructivism: implications for the design and delivery of instruction. In D.H. Jonassen, Handbook of Research for Educational Communications and Technology (pp. 170-198). New York: Macmillan.

Ferber, J. (1999). Multi-agent Systems. Reading: Addison-Wesley.

Field, J. (2001). Lifelong education. International Journal of Lifelong Education, 20(1/2), 315.

Fischer, G., \& Ostwald, J. (2002). Transcending the Information Given: Designing learning 
Environments for Informed Participation. Paper presented at the Proceedings of ICCE 2002 International Conference on Computers in Education, Auckland, New Zealand. Fowler, M. (2000). UML distilled (second edition ed.). Upper Saddle River, NJ: AddisonWesley.

Gilbert, N. (1995). Emergence in social simulation. In N. Gilbert and R. Conte (eds.), Autonomous Societies: The computer simulation of social life, pp.144-156. London: UCL Press.

Griffin, C. (1999). Lifelong learning and social democracy. International Journal of Lifelong Education, 18(5), 329-342.

Hooff, van den, B., Elving, W., Meeuwsen, J.M. and Dumoulin, C. (2003). Knowledge Sharing in Knowledge Communities. . In M. Huysman, E. Wenger, \& V. Wulf, Communities and Technologies (pp. 119-142). Dordrecht: Kluwer Academic Publishers.

Jarvis, P. (1987). Twentieth century thinkers in adult education. London: Croom Helms. Jennings, N.R. (1998). A Roadmap of Agent Research and Development. Autonomous Agents and Multi-agent Systems, 1(1), 7-38.

Kauffman, S. (1995). At Home in the Universe. Oxford: Oxford University Press.

Koper, E. J. R., \& Manderveld, J. M. (in press). Educational modelling language: modelling reusable, interoperable, rich and personalised units of learning. British Journal of Educational Technology.

Koper, E. J. R., \& Sloep, P. (2003). Learning Networks: connecting people, organizations, autonomous agents and learning resources to establish the emergence of effective lifelong learning. Heerlen: Open University of the Netherlands.Retrieved Www.learningnetworks.org

Koper, E.J.R. (2001). Modelling Units of Study from a Pedagogical Perspective: the pedagogical metamodel behind EML. Heerlen: Open Universiteit Nederland. Retrieved October 3, 2003, from http://eml.ou.nl/introduction/docs/pedmetamodel.pdf

Koper, R., \& Van Es, R. (2004). Modeling units of learning from a pedagogical perspective. London: RoutledgeFalmer.

Lave, J., \& Wenger, E. (1991). Situated learning: Legitimate peripheral participation. Cambridge: Cambridge University Press.

LD (2003). IMS Learning Design. Information Model, Best Practice and Implementation Guide, Binding document, Schemas. Retrieved October 19, 2003, from 
http://www.imsglobal.org/learningdesign/index.cfm

LOM (2003). IMS-LOM Metadata. Binding document, Schemas. Retrieved October 3, 2003, from http://www.imsglobal.org/metadata/index.cfm

Maturana, H., \& Varela, F.J. (1992). The Tree of Knowledge: The Biological Roots of Human Understanding. Rev.Ed. Boston: Shambhala/New Science Press.

Merrill, M.D. (2003). First Principles of Instruction. Retrieved October 3, 2003, from http://www1.moe.edu.sg/itopia/download/abstracts/Applying\%20First Principles of Instruction to Technology-Based Education.pdf

OMG (2003). UML Specification, version 1.4. Retrieved October 14, 2003, from http://www.omg.org/technology/documents/formal/uml.htm

Paas, F. \& Firssova, O. (2004) Usability evaluation of integrated e-learning, in W. Jochems, J.

Van Merriënboer \& E. J. R. Koper (Eds) Integrated eLearning (London, RoutledgeFalmer).

Preece, J. (2000). Online Communities: designing usability, supporting sociability. Chichester: Wiley.

Prietula, M.J., Carley, K.M., \& Gasser, L. (1998). A computational approach to organizations and organizing. In M.J. Prietula, K.M. Carley, \& L. Gasser, Simulating Organizations, (pp. 13-19).Cambridge: MIT Press.

QTI (2003). IMS Question and Test Interoperability. Information Model, Best Practice and Implementation Guide, Binding document, Schemas. Retrieved October 19, 2003, from http://www.imsglobal.org/question/index.cfm

Ragget, P. (1996). The learning society, challenges and trends. London: Routledge.

RDF (2003). Resource Description Format (RDF). Retrieved October 14, 2003, from http://www.w3c.org/RDF/

Reigeluth, C.M. (1999). What is Instructional-Design Theory and How is it Changing? In C.M. Reigeluth, Instructional-Design Theories and Models (pp. 5-30). London: Lawrence Erlbaum.

Retallick, J., Cocklin, B., \& Coombe, K. (1999). Learning Communities in Education. London: Routledge.

Robson, C. (2002). Real World Research. A resource for Social Scientists and PractitionerResearchers. Second Edition Oxford: Blackwell Publishing.

Schuetze, H. G. S. M. (2000). Higher education and lifelong learners, international perspectives on change. London: RoutledgeFalmer.

Shaffer, C., \& Anundsen, K. (1993). Creating Community Anywhere. New York: Perigee 
Books.

Smith, M. K. (1996, 2001, September 22, 2002). 'Lifelong learning', the encyclopedia of informal education, July 2003, from http://www.infed.org/lifelonglearning/b-life.htm

Tattersall, C., Manderveld, J., Van den Berg, B., Van Es, R., Janssen, J., Waterink, W., et al. (2003). Road Mapping (ROMA). Heerlen: Open University of the Netherlands.

Thibaut, J. \& Kelly, H. (1959) The Social Psychology of Groups (New York, Wiley).

Tuijnman, A. v. d. K. M. (1992). Learning across the lifespan, theories, research, policies. Oxford: Pergamon Press.

Varela, F.J., Thompson, E., \& Rosch, E. (1991). The Embodied Mind: Cognitive Science and Human Experience. Cambridge: MIT Press.

Waldrop, M. (1992). Complexity: The Emerging Science at the Edge of Chaos. New York: Simon \& Schuster.

Wasserman, S., \& Faust, K. (1994). Social network analysis : methods and applications. Cambridge ; New York: Cambridge University Press.

Wilson, B., \& Ryder, M. (1998). Distributed Learning Communities: an alternative to designed instructional systems. submitted to Educational Technology Research and Development, from http://carbon.cudenver.edu/ bwilson/dlc.html 